Research Article

\title{
Evaluation of Transfer Efficiency between Subway and Bus Based on the Interval Number Ranking Method by Employing Probability Reliability: Taking Ningbo for Example
}

\author{
Zhenyu Chen, ${ }^{1,2}$ Zhengfeng Huang $\mathbb{D}^{1,2}$ Lingli Yang, ${ }^{1,2}$ and Pengjun Zheng ${ }^{1,2}$ \\ ${ }^{1}$ Faculty of Maritime and Transportation, Ningbo University, Ningbo 315211, China \\ ${ }^{2}$ Jiangsu Province Collaborative Innovation Center for Modern Urban Traffic Technologies, Ningbo 315211, China
}

Correspondence should be addressed to Zhengfeng Huang; huangzhengfeng@nbu.edu.cn

Received 8 September 2021; Revised 28 October 2021; Accepted 10 November 2021; Published 26 November 2021

Academic Editor: Giulio E. Cantarella

Copyright ( $) 2021$ Zhenyu Chen et al. This is an open access article distributed under the Creative Commons Attribution License, which permits unrestricted use, distribution, and reproduction in any medium, provided the original work is properly cited.

\begin{abstract}
In recent years, the construction and operation of urban subways have been gradually increasing in developing countries. In the next step, more attention should be paid to the transfer efficiency between subway and bus so as to improve the travel efficiency of more urban residents. This paper uses the probability credibility interval number ranking method to evaluate the bus transfer efficiency. Firstly, this study obtains the dynamic transfer time data by matching individual smart card and subway/bus global positioning system (GPS) records, which is used to evaluate the transfer efficiency of corresponding subway stations. Then, we establish a probability density function to represent the characteristic information of transfer time. Accordingly, the probability reliability model of the order relation of interval numbers can be constructed. In the end, the method is applied to evaluate the transfer efficiency between subway and bus stations in Ningbo. Compared to the traditional interval number ranking method, the evaluation result shows that this method can get a more objective transfer efficiency order relation. The reason is that this method can not only consider the random feature of transfer time but also make use of the data distribution characteristics. This method could be applied to obtain the stations with relatively low transfer efficiency and the feedback can be used for bus line operation and station layout improvement.
\end{abstract}

\section{Introduction}

The subway system grew rapidly in several developing countries. The beginning of the 21st century marks the great development of subways in China. By the end of the year 2019, 37 cities in the Chinese mainland area have opened subways. There are 150 subway operation lines in China, with a total length of $5179.6 \mathrm{~km}$. However, a lack of sense of passenger-flow cultivation and connection during subway operation results in low-intensity passenger flow. In 2019, there were 18 cities (accounting for 48.65\%) with a maximum daily passenger flow of less than 1 million. Meanwhile, it is worth pointing out that the population is huge in these cities. Hence, if the transfer efficiency between subway and bus can be further improved, it is expected to increase daily commuting and leisure travel by subway. Then, it contributes to not only the occupancy-rate increase of public transport but also the road congestion mitigation.

There are many researches on improving the operation efficiency of public transport. For example, Sun et al. [1] built the transfer optimization model of the county transit network. The model that maximized the synchronization reach operates in the "end-point connection," which is the most suitable layout mode by analyzing the characteristics of county transit passenger flow. Chiva et al. [2] analyzed the efficiency of Bluetooth for the application in the anonymous detection of traveler flow, origin-destination, and the density of travelers in public transport. And they carried experiments on subway lines and stations. Roh et al. [3] presented a decision-making process by establishing a regional prioritizing methodology based on the transportation environment satisfaction level, average access time to major 
facilities, public transportation competitiveness, personal vehicle demand, and existing public transit routes. Finally, user satisfaction was analyzed in Jung-gu, Incheon. Memon et al. [4] developed mode choice models to determine the factors that influence single-occupant vehicle travelers' decision to adopt the central business district service. They collected data by an adapted self-administered questionnaire and developed mode choice models through logistic regression modeling. The research outcomes can support policymakers in implementing sustainable modes of public transportation.

Most of the previous studies related to the evaluation of transfer efficiency between subway and bus focus on indirect indicators rather than carrying out a detailed analysis of transfer time. If local governments want to improve the transfer efficiency of public transportation, they need to investigate and understand the current efficiency in detail. However, research in this area has not been carried out in many places. One of the reasons is that the smart card data of subways and buses are stored in different departments, and the extraction of transfer time information is not well implemented. Most of the cities only use the typical transfer time or indirect qualitative indicators of important stations as a reflection of transfer efficiency. Some local researches establish mathematical models to show how to estimate the transfer time. For example, Li et al. [5] analyzed the arrival law of urban subway and bus and established the waiting time model of passengers, by which the transfer times and waiting times under different departure intervals were calculated. Nevertheless, there is a lack of in-depth and direct analysis on the transfer time of subway stations for a city.

Internationally, scholars attach great importance to the acquisition of transfer time data of subway and bus and evaluate the transfer system with the data. For example, Utsunomiya et al. [6] analyzed usage patterns of public transportation using smart card data for Transit Authority in Chicago, Illinois. Nishiuchi et al. [7] sought to comprehend the use of public transportation systems based on smart card data in Kochi City, Japan. Lee et al. [8] used smart card data of Seoul to establish the bus information data set. Then, they calculated the transfer time and average waiting time of each subway station and established a data envelopment analysis model to estimate the transfer efficiency. Finally, they scored the efficiency of 32 transfer stations and put forward improvement strategies. Although many studies have evaluated the transfer time, the methods do not reflect the real distribution of stochastic transfer time, and the evaluation results may be not objective and scientific enough. Nowadays, with transport-related big data increasing substantially, we should better analyze transfer time directly by considering its distribution.

Transfer time is an important index to measure the efficiency of bus-rail transfer. The longer transfer time means that it takes more time for passengers to get off from the subway station to get on the bus. It also means that the transfer efficiency is inefficient and the bus service experience needs to be improved. The transfer time should be expressed by the range of interval numbers because the walking speed and waiting time of passengers are different and the transfer data are discrete rather than continuous variables. And it is helpful to rank the interval numbers to compare the transfer times of different stations. At present, there are many interval number ranking methods used to sort sequences for studied schemes. Dai et al. [9] made use of rough decision entropy measure and interval approximation roughness measure to study the uncertainty measurement for interval-valued information systems. Vahdani et al. [10] adopted a method named elimination and choice translating reality (ELECTRE) to rank a set of alternatives versus a set of criteria to reflect the decision maker's preference. And the ELECTRE method is illustrated by applying it to the problem of supplier selection. Wong and $\mathrm{Hu}$ [11] provided the interval clustering approach (ICA) to evaluate water quality. The method introduced the notion of weightings in the form of intervals, by which interval samples can be analyzed with a view to delineating the important attributes via the interval weights. Han et al. [12] used the approach of indirect least squares (ILS) that formed interval sample data with weekly, monthly, and quarterly data to explore the relationship between the exchange rate of the Australian dollar against the US dollar and the gold price, considering the volatility of variables. Guerra and Stefanini [13] introduced a comparison index for interval ordering based on the generalized Hukuhara difference. And it was proved that the definition of a risk measure guarantees the possibility of quantifying a worst-case loss when solving maximization or minimization problems with intervals. Bhattacharjee et al. [14] used interval number-based logistic regression to find the risk of failure of high-capacity submersible pumps in the power plant. Fu et al. [15] proposed a grey target decisionmaking model of interval numbers based on positive and negative clouts aiming at the multiattribute decision-making problem with incomplete and uncertain attribute weight information and an attribute value of interval numbers. Tian et al. [16] provided an interval number optimization algorithm to solve the flexible optimization design problem in $\mathrm{CO}_{2}$ pipeline transportation. Numerical results showed that the method could solve the flexible optimization problem effectively in the presence of uncertainties. Zhang et al. [17] proposed a risk assessment model based on interval numbers in order to improve the accuracy of the risk assessment results of metro construction projects. In this method, the experts' evaluation information was represented by interval numbers. They used this method to evaluate the construction risk of a section of the shield tunnel of Shenzhen Metro Line 12.

The evaluation methods referred above generally assume that the form of quantitative probability distribution within the interval is unknown. If any, it only obeys a special form of distribution, such as uniform or normal distribution. Qiu et al. [18] proposed an interval number ranking method based on probability reliability, which was available to introduce any probability density function. The method is able to utilize the real distribution pattern of corresponding features under the background of big data. It has the advantage of the fast ranking speed and high solution quality. This method would be used for the evaluation of transfer efficiency between bus and subway in this paper. 
In addition, the transfer time mentioned herein is the time duration started from leaving the station ticket gate and ended at boarding the transfer bus at the nearby stops. The main difference between our research and the previous transfer efficiency evaluation model is that we regard the transfer time as an interval value within a range (for instance, from 3 to 8 minutes) rather than a single value. The research framework of this paper is as follows.

Firstly, design the method to extract the transfer time of residents according to the characteristics of smart card data. In the data process, we should consider the classification of transferable bus lines and the dealing of abnormal values. Secondly, construct the interval number evaluation model of transfer time. It is necessary to standardize the transfer time and establish the probability density function based on the frequency distribution of passenger flow on the timeline. There are another two important steps: construct the probability reliability model considering the order relation of interval numbers and design the operation process of complementary judgment matrix according to the model. Thirdly, take Ningbo as an example to sort and classify the transfer efficiency for each subway station and compare the sorting results with a conventional method of interval number evaluation at last.

\section{Variables and Notation}

The definitions of variables involved in the interval number ranking problem in this paper are shown in Table 1.

\section{Interval Number Ranking Method Based on Probability Reliability}

Figure 1 depicts the concrete steps about using the interval number ranking method based on probability reliability to evaluate the bus and subway transfer efficiency.

Step 1. Collect the interval number of transfer time between subway and bus, and then obtain its probability density function.

Oriented from ticket gates of the subway station, we use the maximum walking distance of $1 \mathrm{~km}$ as the requirement to select transfer bus stops. Then, we choose all bus lines passing through these stops as candidates for passengers to transfer to the subway station. According to the smart card/ GPS records of the subway and these buses, we focus on the data related to transfer and determine the interval number of transfer time.

It is worth noting that most attributes of smart card records and GPS data are different, so it is difficult to obtain transfer time directly. Smart card data contains passenger Identity Document (ID), boarding time stamp, and bus information but no station ID. Nevertheless, GPS data contains station arrival information such as the arrival time of train/bus and station ID. Therefore, it is not clear to see the relation relationship between the passenger ID and the corresponding boarding station. The transfer time could be calculated only if the passenger boarding information at a certain station is a known input. Herein, we need to use the common index word bus ID in the two types of data to establish this relationship. Figure 2 depicts the specific implementation process.

Step 2. Construct a probability reliability matrix that describes the priority relationship between transfer time interval numbers.

If the actual values of interval numbers $\tilde{a}_{i}$ and $\tilde{a}_{j}$ follow probability density functions $f_{i}(x)$ and $f_{j}(x)$, respectively, then the probability reliability in terms of the order relation “ $>$ " and “ $\prec$ " expressing "superior" and “inferior", respectively) is as follows in equations (1) and (2).

$$
\begin{aligned}
& P\left(\widetilde{a}_{j}>\widetilde{a}_{i}\right)=\iint_{y \geq x} f_{i}(x) f_{j}(y) \mathrm{d} x \mathrm{~d} y, \\
& P\left(\tilde{a}_{j} \prec \tilde{a}_{i}\right)=\iint_{y \leq x} f_{i}(x) f_{j}(y) \mathrm{d} x \mathrm{~d} y .
\end{aligned}
$$

The above two equations are used to calculate the probabilities of the relative dominance of interval numbers $\widetilde{a}_{j}$ and $\widetilde{a}_{i}$ separately. Their ride sides show the sum of all of the joint probabilities in the dominant zone. For instance, the right side of equation (1) could calculate the probability that the numbers in $\tilde{a}_{j}$ are larger than those in $\tilde{a}_{i}$. It could be expressed as an integral form of the joint probability density function, and its effective integral area conforms to the condition that the value of factor $j$ is greater than that of $i$.

As to subway stations $i$ and $j$, we assume their transfer time interval numbers are $\widetilde{a}_{i}=\left[a_{i}^{-}, a_{i}^{+}\right]$and $\widetilde{a}_{j}=\left[a_{j}^{-}, a_{j}^{+}\right]$ separately. In addition, we suppose $a_{j}^{+} \geq a_{i}^{+}$. According to the aforementioned formula of probability reliability, we would discuss the order relations by dividing the issue into three cases.

(1) When $a_{i}^{-} \leq a_{j}^{-} \leq a_{i}^{+} \leq a_{j}^{+}$, there is an intersecting relation between the interval ranges of $\tilde{a}_{i}$ and $\tilde{a}_{j}$. The probability reliability of the order relation $\tilde{a}_{j}>\widetilde{a}_{i}$ is described in

$$
P\left(\tilde{a}_{j} \succ \tilde{a}_{i}\right)=\iint_{y \geq x} f_{i}(x) f_{j}(y) \mathrm{d} x \mathrm{~d} y=\int_{a_{i}^{-}}^{a_{j}^{-}} f_{i}(x) \mathrm{d} x+\int_{a_{j}^{-}}^{a_{i}^{+}} \int_{x}^{a_{j}^{+}} f_{i}(x) f_{j}(y) \mathrm{d} x \mathrm{~d} y=1-\int_{a_{i}^{-}}^{a_{j}^{+}} f_{i}(x) F_{j}(x) \mathrm{d} x .
$$

(2) When $a_{j}^{-} \leq a_{i}^{-} \leq a_{i}^{+} \leq a_{j}^{+}$, there is an inclusion relation between the interval ranges of $\tilde{a}_{i}$ and $\tilde{a}_{j}$. The probability reliability of the order relation $\widetilde{a}_{j}>\widetilde{a}_{i}$ is described in 
TABLE 1: Notations in the interval number ranking problem.

\begin{tabular}{|c|c|}
\hline Symbol & Description \\
\hline$I$ & The set of all sequences of interval number $\left\{\widetilde{a}_{1}, \tilde{a}_{2}, \ldots, \tilde{a}_{n}\right\}$ \\
\hline$\tilde{a}_{i}$ & The $i$ th interval number in the sequence, which is represented by $\left[a_{i}^{-}, a_{i}^{+}\right]$ \\
\hline$f_{i}(x)$ & The probability density of variable $x$ in the $i$ th interval \\
\hline$F_{i}(x)$ & The probability that the actual value \\
\hline$R$ & $\begin{array}{c}\text { The probability reliability matrix }[n, n] \text { of interval number sequence } I \text {, in which } i \text { th row and } j \text { th column is expressed as } r_{i j} \text {. For } \\
\text { any } r_{i j} \in R \text {, it satisfies } r_{i j}=P\left(x_{i}>x_{j}\right)\end{array}$ \\
\hline$r_{i j}$ & $i$ th interval is larger than the $j$ th interval \\
\hline$C$ & $\begin{array}{l}\text { The complementary judgment matrix }[n, n] \text { of interval number sequence, in which the element } c_{i j} \text { is used to express the priority of } \\
\qquad i \text { th interval number to } j \text { th one }\end{array}$ \\
\hline$c_{i j}$ & $\begin{array}{l}\text { Complementary judgment element, following the law that when } \tilde{a}_{i}>\tilde{a}_{j} \text {, then } c_{i j}=1 \text {; when } \tilde{a}_{i}<\tilde{a}_{j} \text {, then } c_{i j}=-1 \text {; when } \tilde{a}_{i}=\tilde{a}_{j} \text {, } \\
\text { then } c_{i j}=0\end{array}$ \\
\hline$\lambda_{i}$ & The relative priority of the interval number $\tilde{a}_{i}$ on the sequence set $I$, which can be calculated by $\sum_{j=1}^{n} c_{i j}$ \\
\hline
\end{tabular}

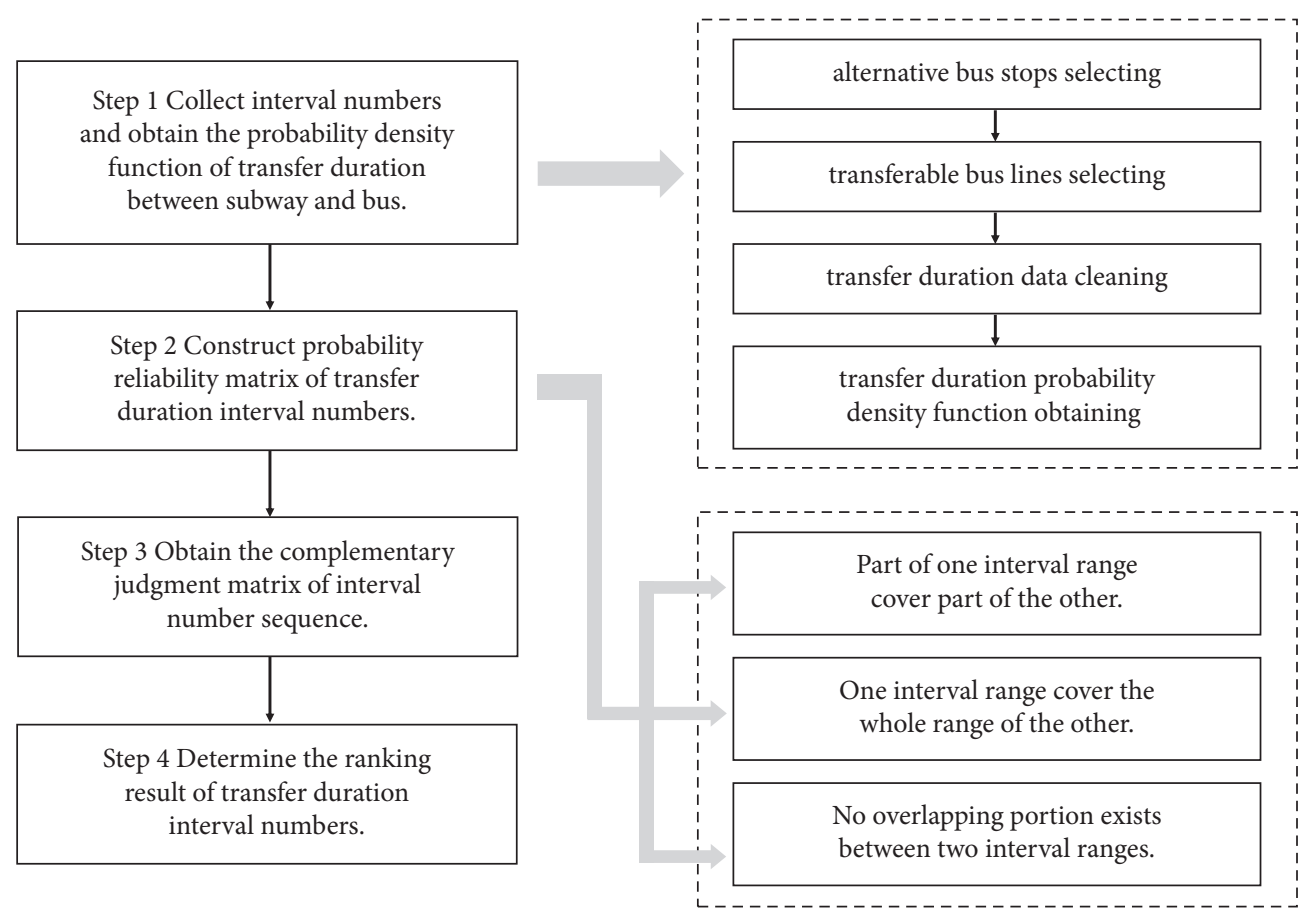

FIgURE 1: Interval number ranking method based on transfer time between subway and bus.

$$
P\left(\widetilde{a}_{j} \succ \widetilde{a}_{i}\right)=\iint_{y \geq x} f_{i}(x) f_{j}(y) \mathrm{d} x \mathrm{~d} y=\int_{a_{i}^{-}}^{a_{i}^{+}} f_{i}(x) \mathrm{d} x \int_{x}^{a_{j}^{+}} f_{j}(y) \mathrm{d} y=1-\int_{a_{i}^{-}}^{a_{i}^{+}} f_{i}(x) F_{j}(x) \mathrm{d} x .
$$

(3) When $a_{i}^{-} \leq a_{i}^{+} \leq a_{j}^{-} \leq a_{j}^{+}$, there is an alienation relation between the interval ranges of $\tilde{a}_{i}$ 和 $\tilde{a}_{j}$. The probability reliability of the order relation $\tilde{a}_{j}>\tilde{a}_{i}$ is described in

$$
P\left(\tilde{a}_{j} \succ \tilde{a}_{i}\right)=\iint_{y \geq x} f_{i}(x) f_{j}(y) \mathrm{d} x \mathrm{~d} y=\int_{a_{i}^{-}}^{a_{i}^{+}} f_{i}(x) \mathrm{d} x \int_{a_{j}^{-}}^{a_{j}^{+}} f_{j}(x) \mathrm{d} y=1 .
$$

The above 3 order relations of interval numbers correspond to (a), (b), and (c) of Figure 3 separately. The shaded area represents the positions where factor $j$ takes dominance.
The joint probabilities are calculated in this area. These charts could help to understand the derivation process of formulas (3)-(5). 


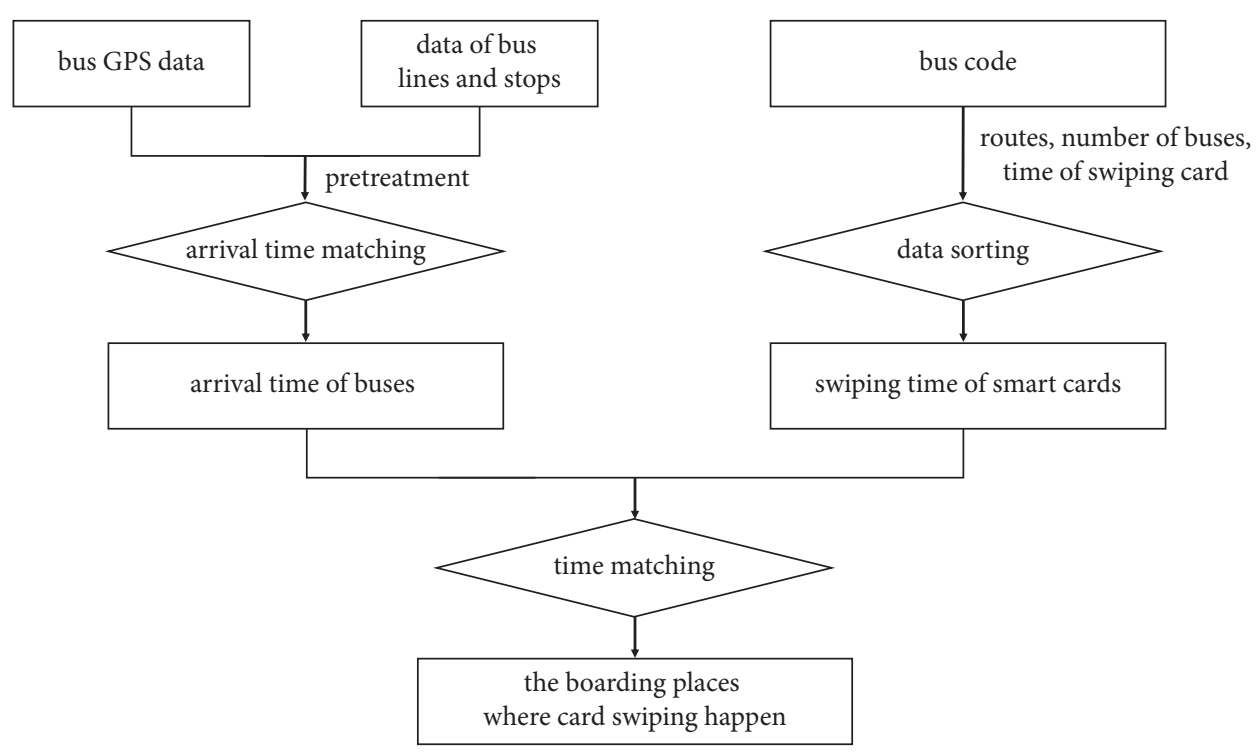

FIGURE 2: Matching process of passenger and station IDs.

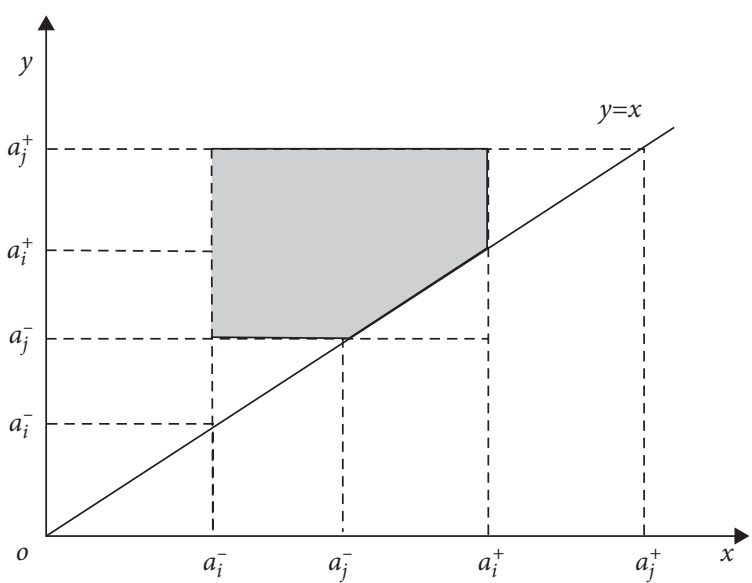

(a)

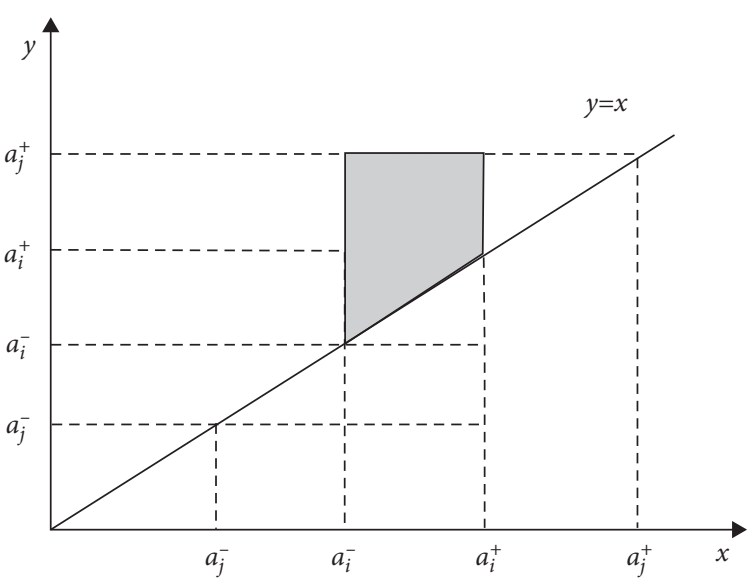

(b)

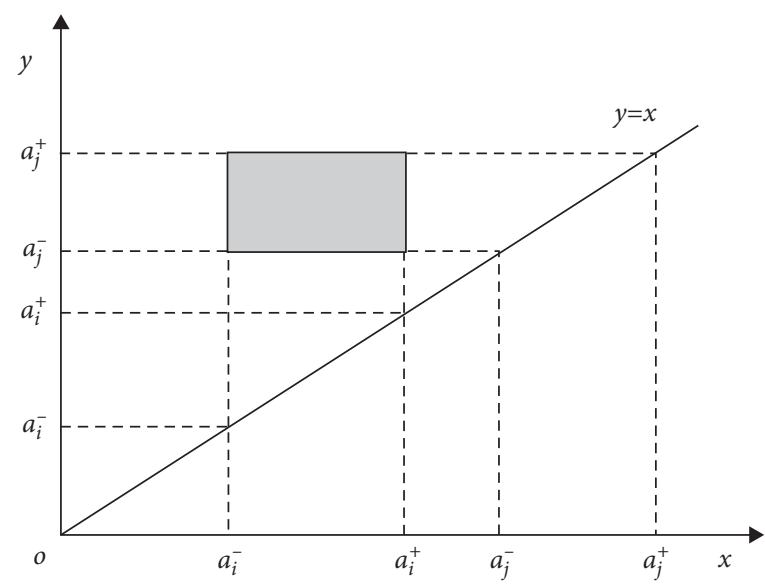

(c)

Figure 3: 3 order relations of interval numbers. 
To sum up, the conclusions are described as in equations (6)-(8):

$$
\begin{gathered}
P\left(\tilde{a}_{j}>\widetilde{a}_{i}\right)= \begin{cases}1, & a_{i}^{-} \leq a_{i}^{+} \leq a_{j}^{-} \leq a_{j}^{+}, \\
1-B_{1}, & a_{j}^{-} \leq a_{i}^{-} \leq a_{i}^{+} \leq a_{j}^{+}, \\
1-B_{2}, & a_{i}^{-} \leq a_{j}^{-} \leq a_{i}^{+} \leq a_{j}^{+},\end{cases} \\
B_{1}=\int_{a_{i}^{-}}^{a_{i}^{+}} f_{i}(x) F_{j}(x) \mathrm{d} x, \\
B_{2}=\int_{a_{i}^{-}}^{a_{j}^{+}} f_{i}(x) F_{j}(x) \mathrm{d} x .
\end{gathered}
$$

There are integral terms in $B_{1}$ and $B_{2}$, which makes it difficult to solve them directly. We use the following compound gradient formula (9) to calculate them, where $h$ represents the basic cell width in the integral form, namely, $h=b-a / n$. And $x_{i}=a+i h(i=1,2, \ldots, n-1)$.

$$
\int_{a}^{b} f(x) \mathrm{d} x \approx \frac{h}{2}\left[f(a)+f(b)+2 \sum_{i=1}^{n-1} f\left(x_{i}\right)\right] .
$$

At last, we could construct the probability reliability matrix $R$ based on the calculation of each probability reliability.

Step 3. Obtain the complementary judgment matrix of transfer time.

Obtain the complementary judgment matrix $C$ based on the probability reliability matrix $R$. If $P\left(\tilde{a}_{j}>\widetilde{a}_{i}\right)>0.5$, then $\widetilde{a}_{j}>\widetilde{a}_{i}, c_{i j}=1$. If $P\left(\widetilde{a}_{j}<\widetilde{a}_{i}\right)<0.5$, then $\tilde{a}_{j}<\widetilde{a}_{i}, c_{i j}=-1$. If $P\left(\widetilde{a}_{j}>\widetilde{a}_{i}\right)=0.5$, then $\widetilde{a}_{j}=\widetilde{a}_{i}, c_{i j}=0$.

Step 4. Determine the ranking result of the interval numbers of transfer time.

Summing up the numbers in each row of the matrix $C$, we could get the relative priority of each subway station with respect to transfer time. The result is that if the relative priority of station $i$ is not worse than that of station $j$, then the mathematical language is expressed as $\lambda_{j} \geq \lambda_{i}$. In other words, the higher the relative priority is, the lower the transfer efficiency is. About the reason why the form of summing up could help us compare the relative priority, we would explain it as follows.

(1) As to any interval number $\tilde{a}_{i}, \tilde{a}_{j} \in I$, the necessary and sufficient condition of $P\left(\widetilde{a}_{j}>\tilde{a}_{i}\right) \geq 0.5$ is that $\lambda_{j} \geq \lambda_{i}$ holds

(2) If $\lambda_{i} \geq \lambda_{j} \geq \lambda_{k}$, then $\lambda_{i} \geq \lambda_{k}$

According to these 2 inferences, we could conclude that the greater the sum of certain row's elements of the complementary judgment matrix is, the more forward position the interval number will be, and the more transfer time passengers will spend in the corresponding subway station.

\section{Numerical Case}

We selected Ningbo subway stations as a case to study the issue of the transfer efficiency evaluation. The transfer time of adjacent swiping between subway ticket gate and bus is used as the analysis basis of transfer time. As to the selection of subway stations, we take 11 stations with the largest transfer trips as the research object. The locations of the stations are displayed in the red dots in Figure 4.

The transfer time data was sourced from the working days of the second week of September 2019, and the average daily total transfer volume of these transfer stations reached 5331 trips per day. In this study, we extracted 3 indices of the smart card data to build the dataset. Selected indices to acquire the data required to evaluate transfer efficiency are passenger ID, subway/bus ID, and transaction timestamp. And extracted GPS data include subway/bus ID, arrival station, arrival timestamp. The transfer time between subway and bus can be acquired by our aforementioned method to combine the two kinds of data. During the data analysis, we obtain some intermediate variables for each subway station: the number of surrounding bus stops, the number of bus lines, and the maximum and minimum transfer times. Table 2 shows the intermediate data of 11 subway stations. The number of transfers per minute of each station is shown in Table 3.

According to the transfer time data, the maximum transfer time of most sites is less than 20 minutes, which is in line with people's usual tolerance limit. The maximum transfer time in crowded areas such as Gulou Station and Dongmenkou Station reached 20-30 minutes. The reasons come from many aspects. On the one hand, bus stops are dense in these areas, so people may have a chance to choose farther stations to transfer, leading to the increase of transfer time. On the other hand, buses from the suburbs have low service frequency, so it takes longer for transfer passengers to wait at bus stops.

The box plot of transfer time shown in Figure 5 indicates that the average transfer time in Gulou Station is the largest while the average transfer time and its dispersion in Xiapu Station are the smallest. However, the transfer time of most subway stations is very close. Moreover, the average value can probably be affected by the difference of transfer time distribution of each station, so it may face a challenge in reflecting the typical transfer characteristics of corresponding stations accurately. Therefore, in this efficiency evaluation work, we use the interval number method based on the distribution patterns of these transfer times rather than the average value.

In this paper, we adopted the interval number ranking method based on probability reliability mentioned above for research. The transfer times of 11 stations, including Dongmenkou Station, Donghuan South Road Station, Fuqing North Road Station, Gaoqiao Station, Gulou Station, Haiyan North Road Station, Nijiayan Station, Shengmo Road Station, Shiji Avenue Station, Ximenkou Station, and Xiapu Station, are respectively, expressed by interval numbers $\tilde{a}_{1}=[1,23], \tilde{a}_{2}=[1,10], \tilde{a}_{3}=[3,15], \tilde{a}_{4}=[2,21]$, $\tilde{a}_{5}=[0,30], \quad \tilde{a}_{6}=[0,17], \quad \tilde{a}_{7}=[1,15], \quad \tilde{a}_{8}=[1,14]$, $\tilde{a}_{9}=[0,12], \quad \tilde{a}_{10}=[1,14]$, and $\tilde{a}_{11}=[1,10]$. The upper bound and lower bound of the transfer time, as well as its probability intensity function, come from the data integration of individual passengers. First of all, we collect each 


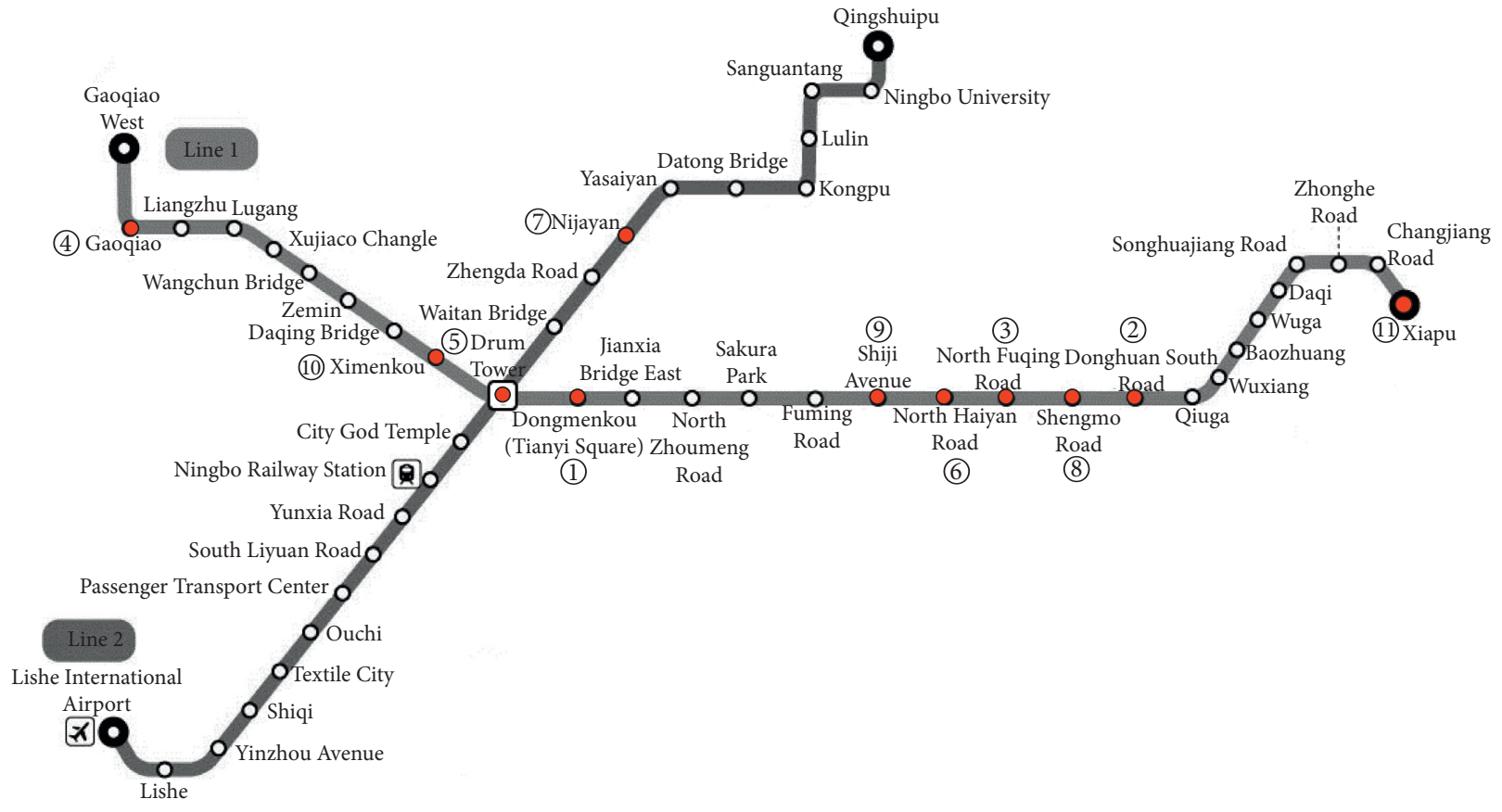

FIGURE 4: Locations of 11 selected transfer stations (codes listed beside the stations).

TABle 2: Data description.

\begin{tabular}{|c|c|c|c|c|c|}
\hline \multirow{2}{*}{ Codes } & \multirow{2}{*}{ Transfer station } & \multirow{2}{*}{ Number of transfer stops } & \multirow{2}{*}{ Number of bus lines } & \multicolumn{2}{|c|}{ Transfer time } \\
\hline & & & & Lower limit & Upper limit \\
\hline 1 & Dongmenkou Station & 12 & 35 & $1 \mathrm{~min} 33 \mathrm{sec}$ & $23 \mathrm{~min} 58 \mathrm{sec}$ \\
\hline 2 & Donghuan South Road Station & 3 & 12 & $1 \mathrm{~min} 17 \mathrm{sec}$ & $10 \mathrm{~min} 56 \mathrm{sec}$ \\
\hline 3 & Fuqing North Road Station & 5 & 21 & $3 \mathrm{~min} 59 \mathrm{sec}$ & $15 \mathrm{~min} 57 \mathrm{sec}$ \\
\hline 4 & Gaoqiao Station & 2 & 10 & $2 \min$ & $21 \mathrm{~min} 37 \mathrm{sec}$ \\
\hline 5 & Gulou Station & 10 & 44 & $56 \mathrm{sec}$ & $30 \mathrm{~min} 41 \mathrm{sec}$ \\
\hline 6 & Haiyan North Road Station & 8 & 14 & $38 \mathrm{sec}$ & $17 \mathrm{~min} 59 \mathrm{sec}$ \\
\hline 7 & Nijiayan Station & 5 & 12 & $1 \mathrm{~min} 50 \mathrm{sec}$ & $15 \mathrm{~min} 58 \mathrm{sec}$ \\
\hline 8 & Shengmo Road Station & 6 & 12 & $1 \mathrm{~min} 49 \mathrm{sec}$ & $14 \mathrm{~min} 56 \mathrm{sec}$ \\
\hline 9 & Shiji Avenue Station & 4 & 16 & $52 \mathrm{sec}$ & $12 \mathrm{~min} 48 \mathrm{sec}$ \\
\hline 10 & Ximenkou Station & 6 & 25 & $1 \mathrm{~min} 25 \mathrm{sec}$ & $15 \mathrm{~min}$ \\
\hline 11 & Xiapu Station & 2 & 10 & $1 \mathrm{~min} 2 \mathrm{sec}$ & $10 \mathrm{~min} 57 \mathrm{sec}$ \\
\hline
\end{tabular}

TABLE 3: The number of transfers of each station with group spacing of 1 minute.

\begin{tabular}{|c|c|c|c|c|c|c|c|c|c|c|c|}
\hline \multirow{2}{*}{ Transfer time } & \multicolumn{11}{|c|}{ Station } \\
\hline & 1 & 2 & 3 & 4 & 5 & 6 & 7 & 8 & 9 & 10 & 11 \\
\hline $0-1 \mathrm{~min}$ & 0 & 0 & 0 & 0 & 5 & 35 & 0 & 0 & 10 & 0 & 0 \\
\hline $1-2 \mathrm{~min}$ & 56 & 19 & 0 & 95 & 65 & 393 & 5 & 5 & 202 & 80 & 313 \\
\hline $2-3 \mathrm{~min}$ & 204 & 152 & 15 & 115 & 242 & 44 & 51 & 95 & 233 & 292 & 521 \\
\hline $3-4 \mathrm{~min}$ & 191 & 217 & 81 & 85 & 333 & 40 & 175 & 191 & 306 & 318 & 470 \\
\hline $4-5 \mathrm{~min}$ & 144 & 275 & 112 & 85 & 301 & 61 & 244 & 164 & 235 & 343 & 581 \\
\hline $5-6 \mathrm{~min}$ & 205 & 188 & 202 & 90 & 354 & 40 & 214 & 219 & 279 & 237 & 319 \\
\hline $6-7 \mathrm{~min}$ & 101 & 233 & 169 & 125 & 316 & 25 & 227 & 170 & 238 & 202 & 210 \\
\hline $7-8 \mathrm{~min}$ & 99 & 179 & 184 & 80 & 305 & 39 & 180 & 200 & 155 & 258 & 195 \\
\hline $8-9 \min$ & 152 & 214 & 175 & 84 & 281 & 46 & 125 & 210 & 154 & 112 & 147 \\
\hline $9-10 \mathrm{~min}$ & 29 & 151 & 94 & 82 & 222 & 10 & 115 & 157 & 205 & 128 & 204 \\
\hline $10-11 \mathrm{~min}$ & 94 & 122 & 85 & 50 & 228 & 45 & 109 & 54 & 108 & 125 & 110 \\
\hline $11-12 \mathrm{~min}$ & 0 & 109 & 75 & 21 & 180 & 25 & 90 & 71 & 100 & 140 & 0 \\
\hline $12-13 \mathrm{~min}$ & 0 & 108 & 79 & 92 & 144 & 24 & 84 & 60 & 65 & 74 & 0 \\
\hline
\end{tabular}


TABle 3: Continued.

\begin{tabular}{|c|c|c|c|c|c|c|c|c|c|c|c|}
\hline \multirow{2}{*}{ Transfer time } & \multicolumn{11}{|c|}{ Station } \\
\hline & 1 & 2 & 3 & 4 & 5 & 6 & 7 & 8 & 9 & 10 & 11 \\
\hline $13-14 \mathrm{~min}$ & 0 & 51 & 39 & 61 & 145 & 10 & 71 & 94 & 0 & 76 & 0 \\
\hline $14-15 \mathrm{~min}$ & 0 & 31 & 61 & 53 & 142 & 24 & 46 & 45 & 0 & 75 & 0 \\
\hline $15-16 \mathrm{~min}$ & 0 & 39 & 0 & 36 & 90 & 45 & 29 & 0 & 0 & 0 & 0 \\
\hline $16-17 \mathrm{~min}$ & 0 & 40 & 0 & 45 & 103 & 25 & 0 & 0 & 0 & 0 & 0 \\
\hline $17-18 \mathrm{~min}$ & 0 & 54 & 0 & 33 & 100 & 29 & 0 & 0 & 0 & 0 & 0 \\
\hline $18-19 \min$ & 0 & 22 & 0 & 31 & 70 & 0 & 0 & 0 & 0 & 0 & 0 \\
\hline 19-20 min & 0 & 29 & 0 & 29 & 54 & 0 & 0 & 0 & 0 & 0 & 0 \\
\hline $20-21 \mathrm{~min}$ & 0 & 9 & 0 & 11 & 31 & 0 & 0 & 0 & 0 & 0 & 0 \\
\hline $21-22 \mathrm{~min}$ & 0 & 21 & 0 & 0 & 40 & 0 & 0 & 0 & 0 & 0 & 0 \\
\hline $22-23 \mathrm{~min}$ & 0 & 25 & 0 & 0 & 61 & 0 & 0 & 0 & 0 & 0 & 0 \\
\hline $23-24 \mathrm{~min}$ & 0 & 9 & 0 & 0 & 70 & 0 & 0 & 0 & 0 & 0 & 0 \\
\hline $24-25 \mathrm{~min}$ & 0 & 0 & 0 & 0 & 24 & 0 & 0 & 0 & 0 & 0 & 0 \\
\hline $25-26 \mathrm{~min}$ & 0 & 0 & 0 & 0 & 69 & 0 & 0 & 0 & 0 & 0 & 0 \\
\hline $26-27 \mathrm{~min}$ & 0 & 0 & 0 & 0 & 41 & 0 & 0 & 0 & 0 & 0 & 0 \\
\hline $27-28 \mathrm{~min}$ & 0 & 0 & 0 & 0 & 55 & 0 & 0 & 0 & 0 & 0 & 0 \\
\hline $28-29 \mathrm{~min}$ & 0 & 0 & 0 & 0 & 26 & 0 & 0 & 0 & 0 & 0 & 0 \\
\hline $29-30 \mathrm{~min}$ & 0 & 0 & 0 & 0 & 19 & 0 & 0 & 0 & 0 & 0 & 0 \\
\hline $30-31 \mathrm{~min}$ & 0 & 0 & 0 & 0 & 20 & 0 & 0 & 0 & 0 & 0 & 0 \\
\hline
\end{tabular}

Note: the stations numbered from 1 to 11, respectively, represent Dongmenkou Station, Donghuan South Road Station, Fuqing North Road Station, Gaoqiao Station, Gulou Station, Haiyan North Road Station, Nijiayan Station, Shengmo Road Station, Shiji Avenue Station, Ximenkou Station, and Xiapu Station.

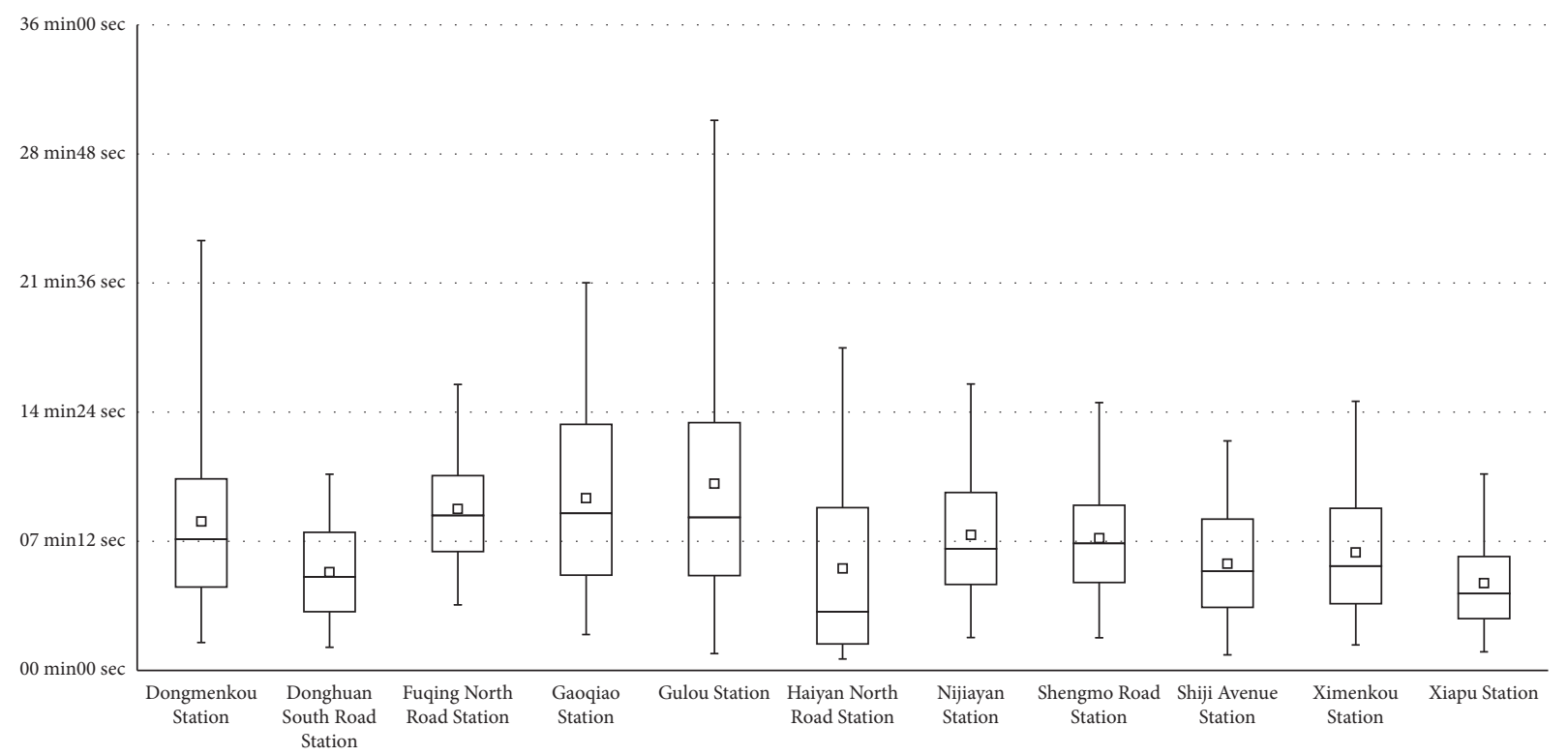

Figure 5: Box plot of transfer time.

transfer time by matching up station-leaving time stamps and bus-boarding time stamps. Then, we add the person to the corresponding time group when his transfer time belongs to the group's range. Let group spacing equal to 1 minute, and then, we could assign the number of transfer passengers to each time group for each station in Table 3. We construct the discrete probability density function from Table 3 directly rather than fitting a continuous function. The reason is that we could just adopt equation (9) to deal with this discrete style to solve the probability reliability matrix. At last, we could acquire the probability reliability matrix $R$ of the interval number sequence $I$. 
TABLE 4: Ranking result of transfer time.

\begin{tabular}{|c|c|c|c|c|c|c|c|c|c|c|}
\hline $\begin{array}{l}\text { Order } \\
\text { Interval } \\
\text { number } \\
\text { variable }\end{array}$ & $\begin{array}{c}1 \\
\tilde{a}_{5}\end{array}$ & $\tilde{a}_{4}$ & $\tilde{a}_{3}$ & $\tilde{a}_{1}$ & $\tilde{a}_{7}$ & $\begin{array}{c}6 \\
\tilde{a}_{8} ; \tilde{a}_{10}\end{array}$ & $\begin{array}{l}7 \\
\tilde{a}_{9}\end{array}$ & $\tilde{a}_{2}$ & $\begin{array}{l}9 \\
\tilde{a}_{6}\end{array}$ & $\begin{array}{c}10 \\
\tilde{a}_{11}\end{array}$ \\
\hline $\begin{array}{l}\text { Subway } \\
\text { station }\end{array}$ & $\begin{array}{l}\text { Gulou } \\
\text { Station }\end{array}$ & $\begin{array}{c}\text { Gaoqiao } \\
\text { Station }\end{array}$ & $\begin{array}{l}\text { Fuqing } \\
\text { North } \\
\text { Road } \\
\text { Station }\end{array}$ & $\begin{array}{c}\text { Dongmenkou } \\
\text { Station }\end{array}$ & $\begin{array}{l}\text { Nijiayan } \\
\text { Station }\end{array}$ & $\begin{array}{c}\text { Shengmo } \\
\text { Road Station; } \\
\text { Ximenkou } \\
\text { Station }\end{array}$ & $\begin{array}{l}\text { Shiji } \\
\text { Avenue } \\
\text { Station }\end{array}$ & $\begin{array}{c}\text { Donghuan } \\
\text { South Road } \\
\text { Station }\end{array}$ & $\begin{array}{c}\text { Haiyan } \\
\text { North } \\
\text { Road } \\
\text { Station }\end{array}$ & $\begin{array}{l}\text { Xiapu } \\
\text { Station }\end{array}$ \\
\hline
\end{tabular}

Note: position number is inversely proportional to transfer time.

$$
R=\left[\begin{array}{ccccccccccc}
0.5 & 0.7277 & 0.4057 & 0.4237 & 0.3636 & 0.6918 & 0.5915 & 0.6072 & 0.6433 & 0.6646 & 0.7777 \\
0.2723 & 0.5 & 0.1659 & 0.2236 & 0.1957 & 0.5050 & 0.2380 & 0.2402 & 0.3965 & 0.3062 & 0.8589 \\
0.5943 & 0.8341 & 0.5 & 0.4930 & 0.4250 & 0.7298 & 0.5493 & 0.7031 & 0.7538 & 0.7545 & 0.8757 \\
0.5763 & 0.7764 & 0.5070 & 0.5 & 0.4197 & 0.7336 & 0.6612 & 0.6758 & 0.7069 & 0.7212 & 0.8168 \\
0.6343 & 0.8043 & 0.5750 & 0.5803 & 0.5 & 0.7725 & 0.7073 & 0.7189 & 0.7442 & 0.7585 & 0.8394 \\
0.3082 & 0.4950 & 0.2702 & 0.2664 & 0.2275 & 0.5 & 0.4290 & 0.4369 & 0.4032 & 0.4669 & 0.5731 \\
0.4085 & 0.7620 & 0.4507 & 0.3388 & 0.2927 & 0.5710 & 0.5 & 0.6446 & 0.6840 & 0.7016 & 0.8108 \\
0.3928 & 0.7598 & 0.2969 & 0.3242 & 0.2811 & 0.5631 & 0.3554 & 0.5 & 0.6811 & 0.5000 & 0.8063 \\
0.3567 & 0.6035 & 0.2462 & 0.2931 & 0.2558 & 0.5968 & 0.3160 & 0.3189 & 0.5 & 04005 & 0.6309 \\
0.3354 & 0.6938 & 0.2455 & 0.2788 & 0.2415 & 0.5331 & 0.2984 & 0.5000 & 0.5995 & 0.5 & 0.7325 \\
0.2223 & 0.1411 & 0.1243 & 0.1832 & 0.1606 & 0.4629 & 0.1892 & 0.1937 & 0.3691 & 0.2675 & 0.5
\end{array}\right] .
$$

As a result, we obtained the complementary judgment matrix of $I$ as follows.

$$
C=\left[\begin{array}{ccccccccccc}
0 & 1 & -1 & -1 & -1 & 1 & 1 & 1 & 1 & 1 & 1 \\
-1 & 0 & -1 & -1 & -1 & 1 & -1 & -1 & -1 & -1 & 1 \\
1 & 1 & 0 & -1 & -1 & 1 & 1 & 1 & 1 & 1 & 1 \\
1 & 1 & 1 & 0 & -1 & 1 & 1 & 1 & 1 & 1 & 1 \\
1 & 1 & 1 & 1 & 0 & 1 & 1 & 1 & 1 & 1 & 1 \\
-1 & -1 & -1 & -1 & -1 & 0 & -1 & -1 & -1 & -1 & 1 \\
-1 & 1 & -1 & -1 & -1 & 1 & 0 & 1 & 1 & 1 & 1 \\
-1 & 1 & -1 & -1 & -1 & 1 & -1 & 0 & 1 & 0 & 1 \\
-1 & 1 & -1 & -1 & -1 & 1 & -1 & -1 & 0 & -1 & 1 \\
-1 & 1 & -1 & -1 & -1 & 1 & -1 & 0 & 1 & 0 & 1 \\
-1 & -1 & -1 & -1 & -1 & -1 & -1 & -1 & -1 & -1 & 0
\end{array}\right] .
$$

The priority degree of each interval number is presented by the value sum in its matrix row; that is, $\lambda_{1}=4, \lambda_{2}=$ $-6, \lambda_{3}=6, \lambda_{4}=8, \lambda_{5}=10, \lambda_{6}=-8, \lambda_{7}=2, \lambda_{8}=-1, \lambda_{9}=-4$, $\lambda_{10}=-1, \lambda_{11}=-10$. According to these values, we could rank the transfer time order in Table 4.

Comparing the sorting results of transfer time interval numbers and average values, it is found that the differences lie in the results of Haiyan North Road Station and Donghuan South Road Station. The transfer time of Haiyan North Road Station is longer than that of Donghuan South Road Station by average ranking, while the opposite result can be found by interval number ranking.
By observing the box plot, it is found that the transfer time of Haiyan North Road Station shows characteristic of right skew distribution, and its average value can be greatly affected by extreme values while the adopted interval number method makes a consideration for the actual distribution characteristics of data during the process of evaluation, which leads to a more objective ranking result.

\section{Discussion}

5.1. Waiting Time Ranking. In this case, the transfer efficiency of some subway stations in the city center is not high. In order to investigate whether the increase of transfer time is caused by unstable bus arrival time at the downtown stops, meanwhile, to examine if the order of the transfer time and the waiting time is consistent, we would compare the waiting time by the adopted interval number ranking method.

In order to calculate the waiting time interval numbers, we should calculate the waiting time for each stop firstly. We subtracted the minimum transfer time of the current bus stop from each transfer time. It could be approximately regarded as the waiting time. After that, we gathered the transfer participants of all the bus stops relative to the same subway station together so as to calculate the waiting time interval number. The waiting time interval numbers of 11 subway stations, including Dongmenkou Station, Donghuan South Road Station, Fuqing North Road Station, Gaoqiao Station, Gulou Station, Haiyan North Road Station, Nijiayan Station, Shengmo Road Station, Shiji Avenue Station, Ximenkou Station, and Xiapu Station, are $\tilde{a}_{1}^{\prime}=[0,21] \tilde{a}_{2}^{\prime}=$ $[0,9] \tilde{a}_{3}^{\prime}=[0,11] \tilde{a}_{4}^{\prime}=[0,19] \tilde{a}_{5}^{\prime}=[0,29] \tilde{a}_{6}^{\prime}=[0,15] \tilde{a}_{7}^{\prime}=$ 
$[0,14] \tilde{a}_{8}^{\prime}=[0,12] \tilde{a}_{9}^{\prime}=[0,11] \tilde{a}_{10}^{\prime}=[0,13]$, and $\tilde{a}_{11}^{\prime}=[0,9]$.

Then, we constructed the probability reliability matrix $R^{\prime}$.

$$
R^{\prime}=\left[\begin{array}{ccccccccccc}
0.5 & 0.5973 & 0.5368 & 0.4090 & 0.3906 & 0.6844 & 0.5146 & 0.5196 & 0.5357 & 0.5460 & 0.6264 \\
0.4072 & 0.5 & 0.4323 & 0.2962 & 0.2929 & 0.6681 & 0.4090 & 0.4150 & 0.4345 & 0.4534 & 0.5000 \\
0.4632 & 0.5677 & 0.5 & 0.3683 & 0.3464 & 0.7067 & 0.4783 & 0.4815 & 0.5000 & 0.5188 & 0.6065 \\
0.5910 & 0.7038 & 0.6317 & 0.5 & 0.4755 & 0.7392 & 0.6100 & 0.6155 & 0.6290 & 0.6334 & 0.7038 \\
0.6094 & 0.7071 & 0.6536 & 0.5245 & 0.5 & 0.7701 & 0.6321 & 0.6375 & 0.6514 & 0.6573 & 0.7310 \\
0.3156 & 0.3319 & 0.2933 & 0.2608 & 0.2299 & 0.5 & 0.2817 & 0.2860 & 0.2975 & 0.3018 & 0.3437 \\
0.4854 & 0.5910 & 0.5217 & 0.3900 & 0.3679 & 0.7183 & 0.5 & 0.5031 & 0.5226 & 0.5343 & 0.6255 \\
0.4804 & 0.5850 & 0.5185 & 0.3845 & 0.3625 & 0.714 & 0.4969 & 0.5 & 0.5168 & 0.5356 & 0.6192 \\
0.4643 & 0.5655 & 0.5 & 0.3710 & 0.3486 & 0.7025 & 0.4774 & 0.4832 & 0.5 & 0.5163 & 0.5979 \\
0.4540 & 0.5466 & 0.4812 & 0.3666 & 0.3427 & 0.6982 & 0.4657 & 0.4644 & 0.4837 & 0.5 & 0.5763 \\
0.3736 & 0.5000 & 0.3935 & 0.2962 & 0.2690 & 0.6563 & 0.3745 & 0.3808 & 0.4021 & 0.4237 & 0.5
\end{array}\right] .
$$

We obtained that the complementary judgment matrix as follows.

$$
C^{\prime}=\left[\begin{array}{ccccccccccc}
0 & 1 & 1 & -1 & -1 & 1 & 1 & 1 & 1 & 1 & 1 \\
-1 & 0 & -1 & -1 & -1 & 1 & -1 & -1 & -1 & -1 & 0 \\
-1 & 1 & 0 & -1 & -1 & 1 & -1 & -1 & 0 & 1 & 1 \\
1 & 1 & 1 & 0 & -1 & 1 & 1 & 1 & 1 & 1 & 1 \\
1 & 1 & 1 & 1 & 0 & 1 & 1 & 1 & 1 & 1 & 1 \\
-1 & -1 & -1 & -1 & -1 & 0 & -1 & -1 & -1 & -1 & -1 \\
-1 & 1 & 1 & -1 & -1 & 1 & 0 & 1 & 1 & 1 & 1 \\
-1 & 1 & 1 & -1 & -1 & 1 & -1 & 0 & 1 & 1 & 1 \\
-1 & 1 & 0 & -1 & -1 & 1 & -1 & -1 & 0 & 1 & 1 \\
-1 & 1 & -1 & -1 & -1 & 1 & -1 & -1 & -1 & 0 & 1 \\
-1 & 0 & -1 & -1 & -1 & 1 & -1 & -1 & -1 & -1 & 0
\end{array}\right] .
$$

The priority degrees of each interval number are $\lambda_{1}^{\prime}=8$, $\lambda_{2}^{\prime}=-9, \quad \lambda_{3}^{\prime}=-5, \quad \lambda_{4}^{\prime}=6, \quad \lambda_{5}^{\prime}=10, \quad \lambda_{6}^{\prime}=4, \quad \lambda_{7}^{\prime}=2, \quad \lambda_{8}^{\prime}-2$, $\lambda_{9}^{\prime}=-5, \lambda_{10}^{\prime}=0$, and $\lambda_{11}^{\prime}=-9$, respectively. The ranking result is shown in Table 5 .

Based on the comparative analysis of the sorting results of transfer time and waiting time, it is found that the Fuqing North Road Station is in a relatively leading position with respect to transfer time, while their waiting time is in a relatively following position. What is more, the order of Ximenkou Station shows an opposite result.

As can be seen from Figure 6, the distance between Fuqing North Road Station and half of the surrounding bus stations is more than 600 meters, which exceeds the limit of people's walking tolerance. Consequently, it takes more walking time during the transfer, causing the increase of total transfer time. Meanwhile, this also indicates that the distance connection between Fuqing North Road Station and the surrounding bus stops is poor, which limits the cultivation of public transport passenger flow.
Xiapu Station and Haiyan North Road Station perform well in both transfer and waiting efficiencies because their transfer stops are close to the subway stations and bus service frequency is high. A shorter transfer distance could reduce the walking time. Higher bus frequency could save the passengers' waiting time. Thus, these two factors could be combined to improve transfer efficiency. As to the waiting time comparison, the surrounding stops of Haiyan North Road Station perform a little better. The reason is that many buses at these stops only serve the nearby financial district and their short line length could contribute to relatively higher bus frequency and less waiting time.

Ximenkou Station is located in the center of the city and there are many buses for transfer, so the waiting time is relatively short. But some bus stops are a little far away from the subway station, such as Changchun RoadStop, Liuzhuang Community Stop, and Daqing Bridge Stop (see Figure 7), so it takes more walking time.

In addition, it is clear that Gulou Station is at the top of the ranking list in both the transfer and waiting times. Figure 8 provides the distribution of bus stops surrounding Gulou Station and the transfer/waiting times of each bus stop. As can be observed from the figure, some of the long transfer times are caused by far stop position, some are caused by long waiting times. As to the long waiting time, it is found that the bus waiting time is generally longer during the morning and evening rush hour. At the same time, it is also found that some suburban buses with low frequency pass through the nearby stop, such as the Fuqiao Street stop. Both the road congestion and low bus service frequency pose the long bus waiting time.

5.2. Comparison between Our Method and Traditional Interval Number Method. In order to confirm the advantage of the interval number ranking method based on probability reliability, it is required to use a conventional interval 
TABLE 5: Ranking result of waiting time.

\begin{tabular}{|c|c|c|c|c|c|c|c|c|c|}
\hline $\begin{array}{l}\text { Order } \\
\text { Interval } \\
\text { number } \\
\text { variable }\end{array}$ & $\begin{array}{c}1 \\
\tilde{a}_{5}^{\prime}\end{array}$ & $\begin{array}{l}2 \\
\tilde{a}_{4}^{\prime}\end{array}$ & $\tilde{a}_{1}^{\prime}$ & $\tilde{a}_{7}^{\prime}$ & $\begin{array}{c}5 \\
\tilde{a}_{8}^{\prime}\end{array}$ & $\begin{array}{c}6 \\
\tilde{a}_{3}^{\prime} ; \tilde{a}_{9}^{\prime}\end{array}$ & $\begin{array}{l}7 \\
\tilde{a}_{10}^{\prime}\end{array}$ & $\begin{array}{c}8 \\
\tilde{a}_{2}^{\prime} ; \tilde{a}_{11}^{\prime}\end{array}$ & $\begin{array}{l}9 \\
\tilde{a}_{6}^{\prime}\end{array}$ \\
\hline $\begin{array}{l}\text { Subway } \\
\text { station }\end{array}$ & $\begin{array}{l}\text { Gulou } \\
\text { Station }\end{array}$ & $\begin{array}{l}\text { Gaoqiao } \\
\text { Station }\end{array}$ & $\begin{array}{l}\text { Dongmenkou } \\
\text { Station }\end{array}$ & $\begin{array}{c}\text { Nijiayan } \\
\text { Station }\end{array}$ & $\begin{array}{l}\text { Shengmo } \\
\text { Road } \\
\text { Station }\end{array}$ & $\begin{array}{c}\text { Fuqing North } \\
\text { Road Station; } \\
\text { Shiji Avenue } \\
\text { Station }\end{array}$ & $\begin{array}{l}\text { Ximenkou } \\
\text { Station }\end{array}$ & $\begin{array}{c}\text { Donghuan South } \\
\text { Road Station; } \\
\text { Xiapu Station }\end{array}$ & $\begin{array}{l}\text { Haiyan } \\
\text { North } \\
\text { Road } \\
\text { Station }\end{array}$ \\
\hline
\end{tabular}

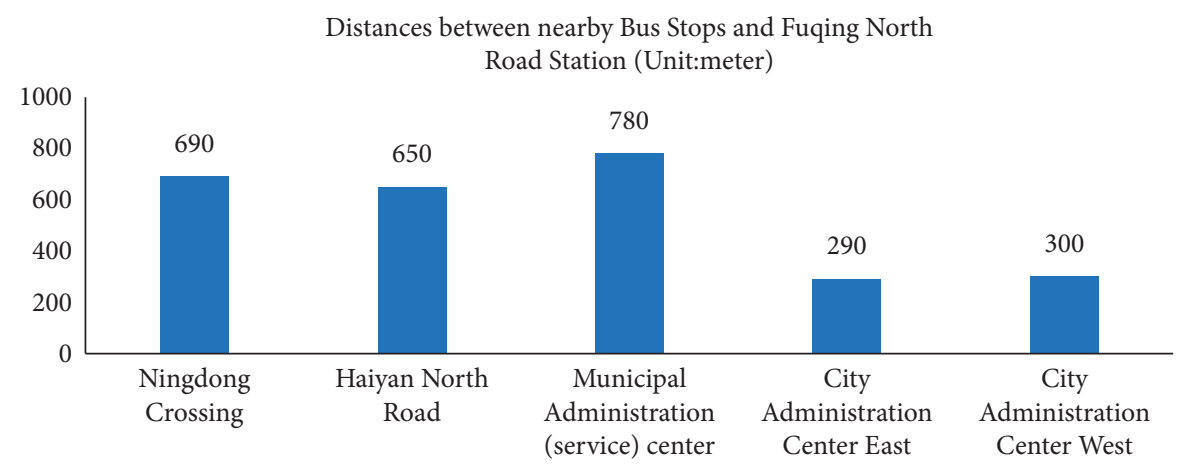

FIgURE 6: Distances between nearby bus stops and Fuqing North Road Station.

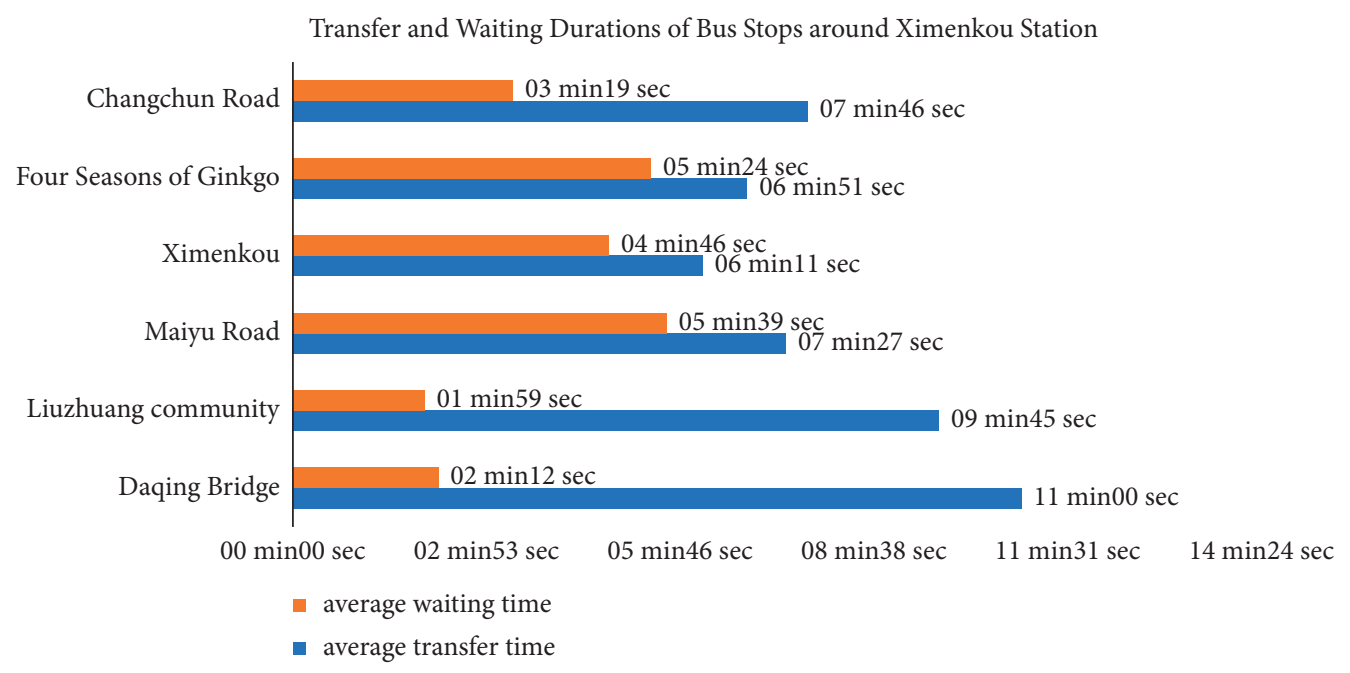

FIgUre 7: Transfer time and waiting times of bus stops around Ximenkou Station.

number method to compare. This traditional method is from the literature [19]. The ranking result of interval numbers is as shown in Table 6.

(i) The transfer time of Fuqing North Road Station is shorter than that of Dongmenkou Station, Haiyan North Road Station, and Nijiayan Station

(ii) The transfer time of Haiyan North Road Station is longer than that of Nijiayan Station

(iii) The transfer time of Xiapu Station is longer than that of Century Avenue Station

In fact, not only the evaluation result of the average values but also the data distribution of transfer times at these stations could support the accuracy and validity of our previous result. We want to emphasize in this part that the varied results come from method divergence. Our method considers more about the information of probability intensity of transfer time and therefore should get a more precise result. For instance, the histogram of the transfer time distribution of Fuqing North Road Station and Haiyan North Road Station has been drawn in Figure 9. If we compare the transfer time of Haiyan North Road Station to that of Fuqing North Road Station by the traditional interval number method, it is known that the ranking result depends solely on the boundary values of interval numbers. The result is that the former one has a wide range and large mean value and thus its time is longer than the latter one. In reality, the quantity of transfer passengers per unit 


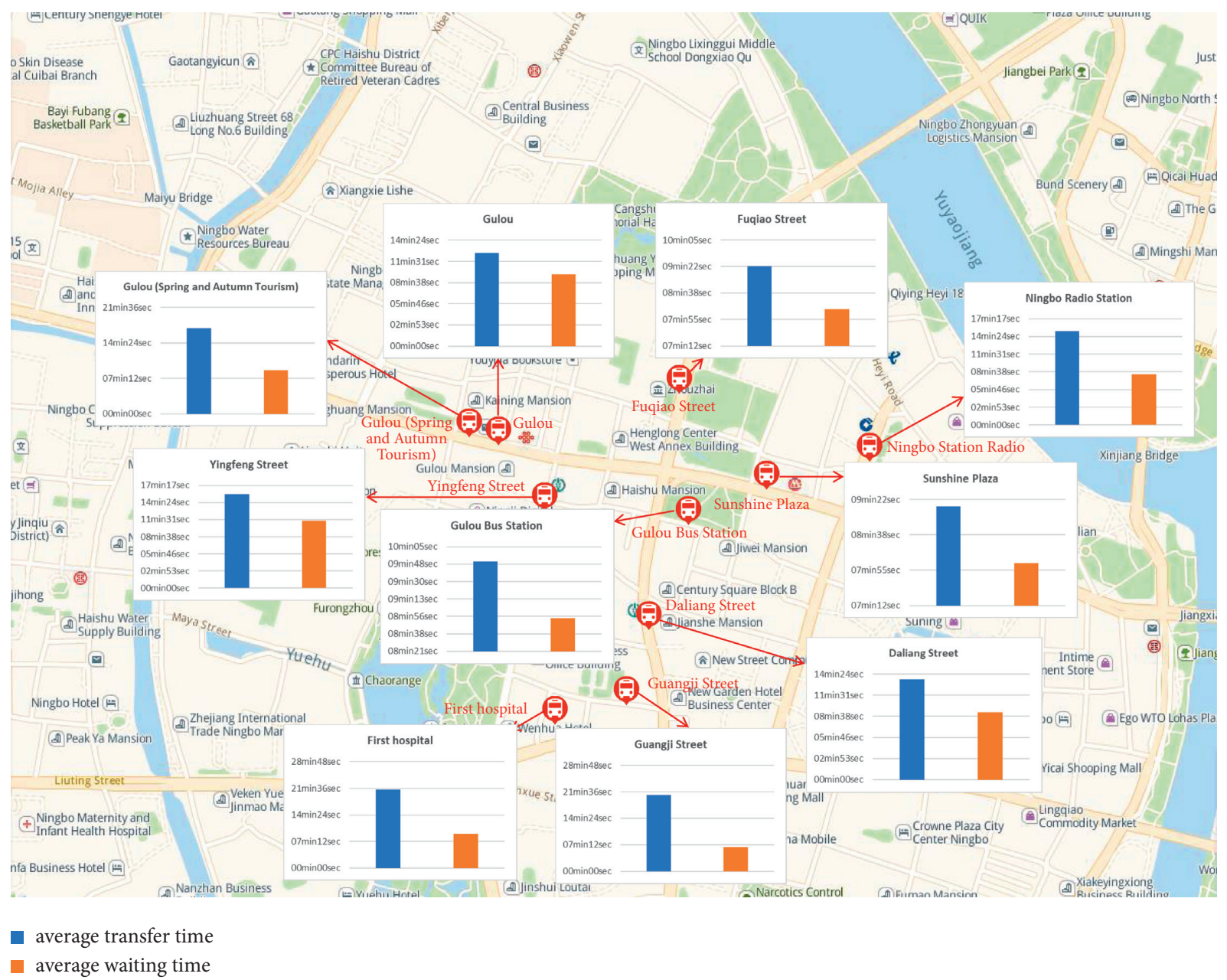

FIGURE 8: Transfer and waiting times of bus stops surrounding Gulou Station. Source: background map is captured from maps.baidu.com.

TABLE 6: Ranking result of interval numbers under traditional interval number method.

\begin{tabular}{lcccccccc}
\hline $\begin{array}{l}\text { Order } \\
\text { Interval } \\
\text { number } \\
\text { variable }\end{array}$ & 1 & 2 & 3 & 4 & 5 & 6 & 7 & 8 \\
\hline $\begin{array}{l}\text { Subway } \\
\text { Station }\end{array}$ & $\tilde{a}_{4} ; \tilde{a}_{5}$ & $\tilde{a}_{1}$ & $\tilde{a}_{6}$ & $\tilde{a}_{7}$ & $\tilde{a}_{3} ; \tilde{a}_{8} ; \tilde{a}_{10}$ & $\tilde{a}_{11}$ & $\tilde{a}_{9}$ & $\tilde{a}_{2}$ \\
\hline $\begin{array}{c}\text { Station, Gulou } \\
\text { Station }\end{array}$ & $\begin{array}{c}\text { Dongmenkou } \\
\text { Station }\end{array}$ & $\begin{array}{c}\text { Haiyan } \\
\text { North Road } \\
\text { Station }\end{array}$ & $\begin{array}{c}\text { Nijiayan } \\
\text { Station }\end{array}$ & $\begin{array}{c}\text { Fuqing North Road } \\
\text { Station, Shengmo Road } \\
\text { Station, Ximenkou Station }\end{array}$ & $\begin{array}{c}\text { Xiapu Station } \\
\text { Station }\end{array}$ & $\begin{array}{c}\text { Avenue } \\
\text { Station }\end{array}$ & $\begin{array}{c}\text { Donghuan } \\
\text { South Road } \\
\text { Station }\end{array}$ \\
\hline
\end{tabular}

According to the ranking result of the traditional method, several stations' order positions are changed when compared to our method.

time is not distributed uniformly. However, this method ignores the specific data distribution of the interval numbers, so the ranking result is not objective. In fact, the interval number ranking method based on probability reliability could overcome this defect. If we analyze them by our method, it could be found that lots of Haiyan North Road Station's transfer times distributed around 1-2 minutes, which makes its time less than the latter one. This result could meet the reality what lots of passengers have experienced. Thus, it demonstrates that our method could achieve a better result than the traditional method with respect to representing the views of more passengers. 


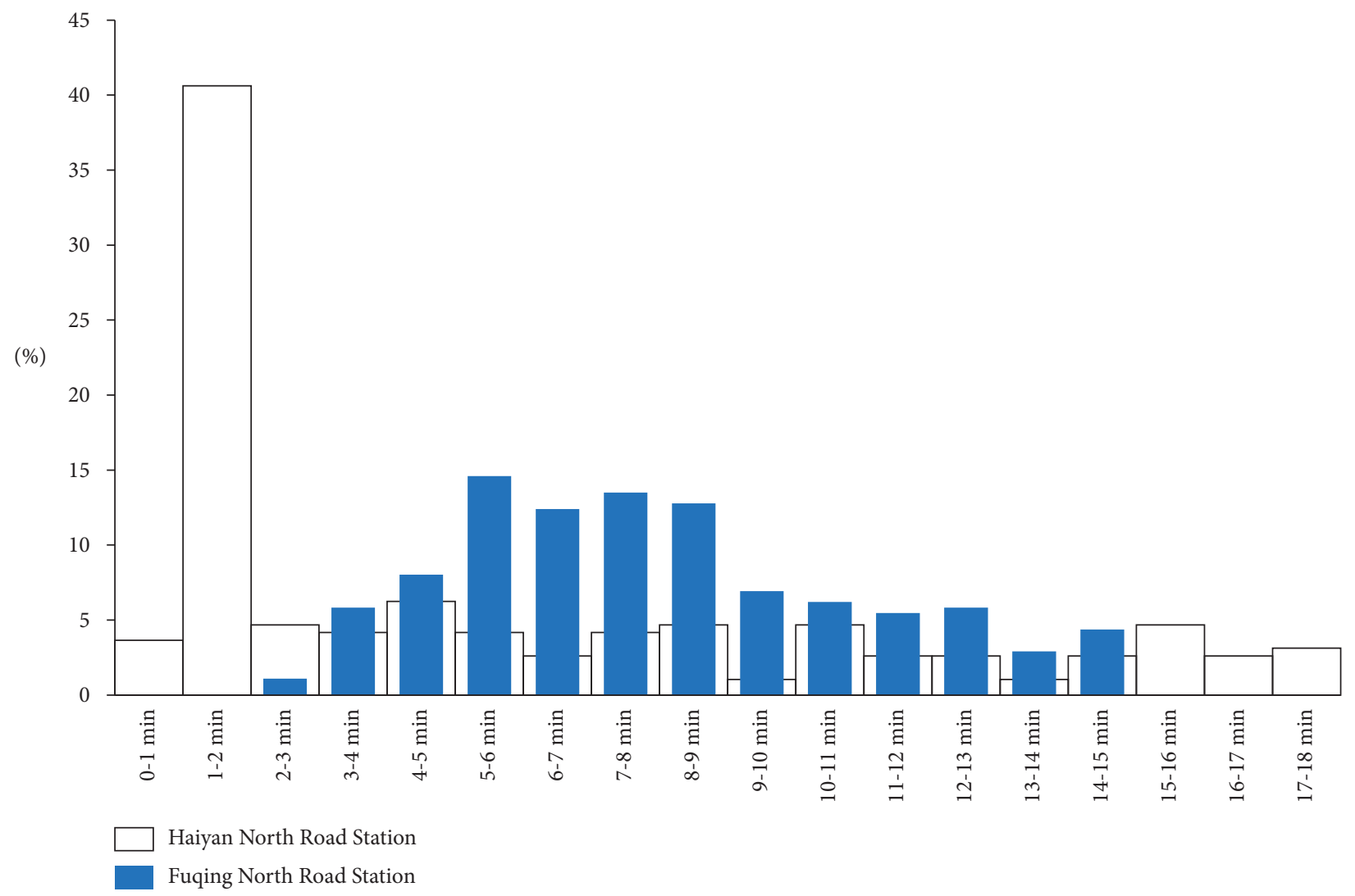

Figure 9: Histogram of data distribution of transfer time.

\section{Conclusions}

This paper mainly applies the probability credibility interval number evaluation method in the sorting direction of transfer efficiency and makes some contributions in finding the connection between the method and the application. In this paper, we carry out a research on the evaluation of transfer efficiency between subway and bus by the probability reliability interval number method, and the ranking results are compared with that made by average values and the conventional interval number method. The data result proves that our method is reliable, which can be used as a guide and reference for further optimizing urban public transport networks in the future. In the future, more evaluation methods can be used for comparison, such as fuzzy evaluation, in order to more comprehensively test the superiority of the interval number evaluation method in the comparison of transfer efficiency.

At the same time, through the evaluation of subway-bus transfer time and waiting time, it is found that there are still some problems in the planning and construction of urban rail transit and bus lines currently, which is also the main reason for the low intensity of urban subway passenger flow. The problems mainly include long waiting times for downtown buses and long distances between bus stops and subway stations located in nondowntown areas.
For the purpose of making the subway play a more remarkable role in promoting urban travel, it is essential to facilitate the connection between subway stations and bus stops, so as to improve the travel efficiency of public transport. If more urban residents tend to choose the mode of public transport, the traffic congestion in cities will be alleviated and the travel satisfaction of urban residents will obtain enhancement. Two advices are given. Firstly, the bus stop deployment surrounding the subway stations should be arranged reasonably. The distance between the bus stop and the subway station should be determined according to people's normal walking tolerance time. Secondly, as to roads with a high level of traffic congestion, we could implement measures such as bus-only lanes and transit signal priority. They would improve the operation efficiency of the bus and reduce the waiting time of transfer passengers.

In the future, we would focus on how our method combined with transit big data could be used in the transit planning and operation field, such as transit network vulnerability analysis $[20,21]$.

\section{Data Availability}

The data used to support the findings of this study are available from the corresponding author upon request. 


\section{Conflicts of Interest}

The authors declare that they have no conflicts of interest.

\section{References}

[1] X. Sun, K. Lin, P. Jiao, Z. Deng, and W. He, "Research on transfer optimization model of county transit network," International Journal of Environmental Research and Public Health, vol. 18, no. 9, Article ID 4962, 2021.

[2] I.-C. Chiva, M. Minea, V.-L. Minea, and A. Semenescu, "Anonymous detection of traveler flows employing bluetooth technologies," Proceedings, vol. 63, no. 1, Article ID 61, 2020.

[3] C.-G. Roh and H. Jeon, "Decision-making process for demand response public transportation service design-a case study in Incheon, Korea," Sustainability, vol. 13, no. 10, Article ID 5574, 2021.

[4] I. A. Memon, S. Kalwar, N. Sahito et al., "Mode choice modeling to shift car travelers towards park and ride service in the city centre of Karachi," Sustainability, vol. 13, no. 10, Article ID 5638, 2021.

[5] Z. Li, Z. Yuan, and Z. Li, "Research on transfer waiting time between subway and bus at multi-modal transit hub," WIT Transactions on Information and Communication Technologies, vol. 48, pp. 943-948, 2014.

[6] M. Utsunomiya, J. Attanucci, and N. H. Wilson, "Potential uses of transit smart card registration and transaction data to improve transit planning," Transportation Research Record, vol. 1971, no. 1, pp. 119-126, 2006.

[7] H. Nishiuchi, T. Todoroki, and Y. Kishi, "A fundamental study on evaluation of public transport transfer nodes by data envelop analysis approach using smart card data," Transportation Research Procedia, vol. 6, pp. 391-401, 2015.

[8] E. H. Lee, H. Lee, S.-Y. Kho, and D.-K. Kim, "Evaluation of transfer efficiency between bus and subway based on data envelopment analysis using smart card data," KSCE Journal of Civil Engineering, vol. 23, no. 2, pp. 788-799, 2019.

[9] J. Dai, W. Wang, Q. Xu, and H. Tian, "Uncertainty measurement for interval-valued decision systems based on extended conditional entropy," Knowledge-Based Systems, vol. 27, no. 3, pp. 443-450, 2012.

[10] B. Vahdani, A. Jabbari, and V. Roshanaei, "Extension of the ELECTRE method for decision-making problems with interval weights and data," International Journal of Advanced Manufacturing Technology, vol. 50, no. 5, pp. 793-800, 2010.

[11] H. Wong and B. Q. Hu, "Application of interval clustering approach to water quality evaluation," Journal of Hydrology, vol. 491, no. 1, pp. 1-12, 2013.

[12] A. Han, K. K. Lai, S. Wang, and S. Xu, "An interval method for studying the relationship between the Australian dollar exchange rate and the gold price," Journal of Systems Science and Complexity, vol. 25, no. 1, pp. 121-132, 2012.

[13] M. L. Guerra and L. Stefanini, "A comparison index for interval ordering based on generalized Hukuhara difference," Soft Computing, vol. 16, no. 11, pp. 1931-1943, 2012.

[14] P. Bhattacharjee, V. Dey, and U. K. Mandal, "Risk assessment by failure mode and effects analysis (FMEA) using an interval number based logistic regression model," Safety Science, vol. 132, Article ID 104967, 2020.

[15] S. Fu, Y.-z. Xiao, H.-j. Zhou, and S.-z. Liu, "Venture capital project selection based on interval number grey target decision model," Soft Computing, vol. 25, no. 6, pp. 4865-4874, 2021.
[16] Q. Tian, D. Zhao, J. Wang, and Z. Li, “A nonlinear interval number programming algorithm for $\mathrm{CO}_{2}$ pipeline transportation design under uncertainties," Greenhouse Gases: Science and Technology, vol. 9, no. 2, pp. 261-275, 2019.

[17] Y. Zhang, J. Zhang, and H. Guo, "A risk assessment method for metro shield tunnel construction based on interval number," Geotechnical and Geological Engineering, vol. 38, no. 4, pp. 4793-4809, 2020.

[18] D. Qiu, C. He, and X. Zhu, "Ranking method research of interval numbers based on probability reliability distribution," Control and Decision, vol. 27, no. 12, pp. 1894-1898, 2012.

[19] Y. Nakahara, M. Sasaki, and M. Gen, "On the linear programming problems with interval coefficients," International Journal of Computer Industrial Engineering, vol. 23, no. 1, pp. 301-304, 1992.

[20] G. Nian, F. Chen, Z. Li, Y. Zhu, and D. J. Sun, "Evaluating the alignment of new metro line considering network vulnerability with passenger ridership," Transportmetrica A, vol. 15, no. 2, pp. 1-34, 2019.

[21] D. Sun and S. Guan, "Measuring vulnerability of urban metro network from line operation perspective," Transportation Research Part A: Policy and Practice, vol. 94, pp. 348-359, 2016. 